\title{
Юрислингвистика
}

Legal Linguistics, 2019, 11, 24-28, doi: https://doi.org/10.14258/leglin(2019)1105

ЛИНГВОЭКСПЕРТОЛОГИЯ $\quad$ УДК 659.4:81'42, ББК Ш 100.3, ГСНТИ 16.21.33, КОД ВАК 10.02.19

\section{О терминологическом смысле понятия «маскировка» в контексте судебной лингвистической экспертизы}

\author{
Е.Л. Дайлоф \\ ФБУ Южного регионального чентра судебной экспертизы Минюста России \\ 344038, Ростов-на-Дону, ул. Ленина, 109/2. E-mail: katerina.dail@rambler.ru
}

В статье рассматривается вопрос об объёме и содержании понятия «маскировка» в контексте судебной лингвистической экспертизы с позиции его терминологической корреляции с явлением криптолалии. При определении понятия маскировки предлагается руководствоваться функционально-прагматическим подходом, то есть ориентироваться в первую очередь на то, с какой целью было использовано то или иное речевое средство (речевой прием, способ передачи информации). В случае маскировки ведущей целью является сокрытие информации от третьих лиц. Опираясь на лингвистические труды В.П. Москвина, в соответствии с изложенным подходом к определению понятия маскировки разграничиваются понятия криптолалии и эвфемии как коммуникативных явлений, противопоставленных друг другу по целевому назначению и составу коммуникантов. При криптолалии: состав участников - адресат, адресант, контрагент (третье лицо, от которого что-то скрывают), цель сокрытие содержания речи от третьих лиц; при эвфемии: состав участников - адресат, адресант, иногда третье лицо, от которого информация не скрывается, цель - смягчение наименования нежелательных предметов и явлений. В контексте противозаконной деятельности участников коммуникации в роли контрагента (третьего лица, от которого скрывается информация) выступает реальный или предполагаемый представитель закона. На примерах из экспертной практики демонстрируется использование альтернативных номинаций (приема криптономазии) с целью сокрытия информации о предмете речи. В заключение отмечается, что в терминологическом смысле понятие маскировки в контексте производства судебной лингвистической экспертизы соотносится с явлением криптолалии и обозначает реализацию в речи коммуникативной установки сокрытия информации от контрагента (третьего лица) посредством использования различных речевых приёмов и средств непрямой коммуникации.

Ключевые слова: судебная лингвистическая экспертиза, маскировка, криптолалия, эвфемия, коммуникативная установка.

Forensic Linguistics

\section{“Disguise” meaning in forensic linguistic expertise}

\section{Dailof E.L}

FBU of the Southern Regional Center for Forensic Expertise of the Ministry of Justice of Russia, Lenin St. 109/2, Rostov-on-Don, 344038. E-mail: katerina.dail@rambler.ru

The article deals with the issue of the scope and content of the concept of "disguise" in the context of forensic linguistic expertise from the perspective of terminological correlation with the phenomenon of cryptolalia. When defining the concept of disguise, it is proposed to be guided by a functional and pragmatic approach, that is, to 
focus primarily on the purpose for which a particular speech tool was used (speech technique, method of information transmission).In the case of masking, the main purpose is to hide information from third parties. Based on the linguistic works of V. P. Moskvin, in accordance with the above stated approach to the definition of the concept of disguise, the concepts of cryptolalia and eupheme as communicative phenomena opposed to each other by purpose and participants are distinguished. When cryptolalia is used participants are: the addressee, the addresser, the counterparty (third person from whom something is hidden); the goal is concealment of speech content from a third party; when eupheme is used participants are: addressee, addresser, sometimes a third party from whom the information is not hidden; the goal is the mitigation of undesirable names of objects and phenomena. When speaking of illegal activities of the participants of communication, a real or alleged representative of the law is seen as the counterparty (a third party from whom the information is hidden). Examples from expert practice demonstrate the use of alternative nominations to hide information about the subject of speech. In conclusion, it is noted that from the point of view of terminology the concept of masking in forensic linguistic expertise is correlated with the phenomenon of cryptology and denotes concealing information from the counterparty (third party) as the objective of communication achieved by various speech techniques and means of indirect communication.

Key words: forensic linguistic expertise, disguise, cryptolalia, eupheme, communicative objective.

В практике производства судебных лингвистических экспертиз вопросы «Имеются ли в тексте/разговоре признаки маскировки его содержательных элементов?», «Каково значение замаскированных элементов и их характеристики?» ставятся на разрешение эксперта по разным категориям дел. Так, потребность в решении данных вопросов возникает при расследовании преступлений, связанных с коррупцией (получение/дача взятки, посредничество), злоупотреблением должностными полномочиями, незаконным оборотом наркотических средств, оружия, боеприпасов, взрывчатых веществ, организацией преступного сообщества и других.

Тем не менее, терминологический статус понятия «маскировка» в судебной лингвистической экспертизе остается, на наш взгляд, достаточно неопределенным и требует теоретического осмысления с целью решения прикладных экспертных задач. В данном случае нельзя не согласиться с мнением Г.В. Кусова о том, что «отсутствие специального терминологического аппарата экспертной деятельности лингвиста (...) не позволяет закончить формирование понятия «системы судебной лингвистической экспертизы» [Кусов 2011].

Понятие «маскировка» не является новым в судебной экспертизе, например, оно закреплено в терминологическом аппарате классической криминалистической экспертизы - автороведческой, и обозначает преднамеренное искажение индивидуальных навыков письменной речи с целью сокрытия личности автора текста, например: «Под маскировкой в речи понимается реализация различными средствами установки адресанта или нескольких адресантов письменного сообщения на сокрытие авторства или состояния автора в момент составления текста» [Гомон 1992].

В общеупотребительном значении лексема «маскировка» (от глагола «маскировать» - скрывать что-н. представлять не тем, что есть в действительности) указывает на использование неких средств, приемов с целью сокрытия истинного положения дел.

При широком подходе к лингвистическому определению понятия маскировки обнаруживается тенденция к опасному объединению в его рамках достаточно широкого круга разнородных языковых явлений, различных речевых стратегий, дискурсивных практик, приемов непрямой коммуникации, имплицитных способов передачи информации. В частности, «маскирующим» потенциалом обладают элиминация, эллипсис, умолчание, эвфемизация, намёк, перифраза, фигуры двусмысленной речи, средства невербальной коммуникации, билингвизация и другие. В то же время использование названных приёмов необязательно предполагает реализацию коммуникативной установки на сокрытие информации и может быть обусловлено, как например в случае элиминации, принципом экономии речевых усилий или, как в случае билингвизации, недостаточным владением неродным языком или затруднением в подборе эквивалента понятия во втором языке. Таким образом, наличие в речи имплицитной составляющей не всегда является признаком маскировки, и при определении объема данного понятия следует, на наш взгляд, руководствоваться функционально-прагматическим подходом, то есть ориентироваться в первую очередь на то, с какой целью было использовано то или иное речевое средство (речевой прием, способ передачи информации). В случае маскировки ведущей целью является сокрытие информации от третьих лиц.

Исходя из вышеизложенного, на наш взгляд, в терминологическом плане понятие маскировки в широком смысле коррелирует с явлением криптолалии - «использованием приёмов и номинативных средств языка в «конспиративной», по выражению В.Д. Бондалетова, или криптофорной функции», а в узком - с речевым приемом криптономазии, заключающемся в конспиративном переименовании объекта речи [Москвин 2007].

Так, при определении понятия маскировки С.В. Доронина говорит о «криптолалической коммуникативной установке» [Доронина 2015]; О.Н. Матвеева - о криптологическом использовании языка, см.: «В целом явление маскировки в лингвистике соотносится с понятием кодирования и криптографии, где язык представляет собой код, знаковую систему, предназначенную для кодирования и передачи информации, а криптологическое использование 
языка - искажение этого кода (придание вербальному знаку значения, отличного от общепринятого, общеизвестного) с целью сокрытия от лиц, которым оно не предназначено» [Матвеева 2015].

В определении, предлагаемом А.Е. Козловым, Я.Х. Сажениной, понятие маскировки раскрывается через феномен эвфемизации, который, в свою очередь, по сути отождествляется с понятием «сокрытие»: «В случае, когда план выражения (очевидно реализованный в высказывании) и план содержания (намеренно завуалированный) не совпадают, можно констатировать использование говорящим средств языковой маскировки, т.е. эвфемизации (сокрытия) денотативной информации или представления ее в заведомо искаженном виде» [Козлов, Саженина 2016].

Опираясь на лингвистические труды В.П. Москвина, мы придерживаемся иной точки зрения, в частности полагаем, что сущность эвфемии как языкового явления не вполне отвечает содержанию понятия маскировки в контексте судебной лингвистической экспертизы с учетом функционально-прагматического подхода к определению понятий. Так, если «эвфемия представляет собой использование словесных зашифровок с целью смягчить, завуалировать, изящно «упаковать» предмет сообщения, оставив все-таки возможность любому носителю языка догадаться, о чем идет речь» [Москвин 2001], то функция сокрытия информации от третьих лиц, что и является целью маскировки, вряд ли может быть реализована.

В данном случае необходимо разграничить понятия эвфемии и криптолалии как языкового явления, в наибольшей степени отвечающего содержанию понятия маскировки. В.П. Москвин указывает, что «эвфемию и криптолалию необходимо развести и трактовать как две абсолютно самостоятельные, функционально противопоставленные речевые стратегии», а «слова, используемые в криптофорной функции, целесообразно именовать не эвфемизмами, а криптонимами» [Москвин 2007]. Основными признаками, отличающими ситуацию криптолалии от ситуации эвфемии, являются целевое назначение (функция) и состав коммуникантов. При криптолалии выделяется следующий состав участников: адресат, адресант, контрагент (третье лицо, от которого чтото скрывают), целью коммуникации является сокрытие содержания речи от третьих лиц. При эвфемии состав участников - адресат, адресант, иногда третье лицо, от которого информация не скрывается; цель - смягчение наименования нежелательных предметов и явлений [Москвин 2007]. В ситуации осуществления коммуникантами противозаконной деятельности в роли контрагента (третьего лица, от которого скрывается информация) выступает реальный или возможный/предполагаемый представитель закона.

Для разграничения эвфемии и криптолалии мы считаем важным следующее наблюдение: «эвфемизм только тогда остается эвфемизмом, когда говорящий производит замену «неудобного слова» на слово «удобное», а не подменяет суть понятия. С помощью эвфемизма нельзя обмануть!» [Никитина 2013]. В структуре эвфемии А.М. Никитина выделяет два компонента: «то, на что заменяется (собственно эвфемизм: «субститут», «нейтральные слова и выражения», «нейтрально или положительно коннотированные наименования») и то, что заменяется (исходное наименование, «стигматический денотат», «антецедент», «отрицательно коннотированные наименования») [Никитина 2013].

При эвфемизации исходное наименование и его эвфемизм имеют общее в той или иной степени семантическое ядро, в то время как при употреблении номинации в криптофорной функции факт реальной действительности и слово, его обозначающее, могут вообще не иметь никаких точек соприкосновения. Например, в экспертной практике был случай наименования ёмкостей (бочек) для перевозки нефтепродуктов словом «девчонки», а при указании объема (тоннажа) этих емкостей использовалась числовые выражения, обозначающие возраст. В результате такой «маскировки» состоялся следующий курьезный в некоторой степени диалог:

М1: Привет, братан! Девчонку хочу, нет сил больше терпеть! Очень хочу!

М2: Какую?

M1: Ну, лет 48-50.

Еще один пример из экспертной практики, демонстрирующий зачастую отсутствие какой бы то ни было семантической связи между реальным объектом и словом, используемым для его номинации. На исследование был представлен телефонный разговор следующего содержания:

M2: Приветствую Ну чё этот. Ну как... как говорили, да? Две рыбы отдашь и все.

М1: Дак... эээ... Две...Блин, поточней бы как-нибудь, чтоб я все понял. Мне поделить то, что должен отдать или чего? Или три рыбы?

M2: Нет... Вот общее у нас получается три штуки?

M1: Да

M2: Вот две отдай, а одну оставь у себя пока.

M1: Хорошо. Понял. Все. Есть.

M2: М-м-м-угу все, все.

M1: Все, все. Понял, а то я хотел соленой рыбы бежать покупать... Елки-палки!

M2: Hет, нет, нет, соленой не надо...(смех).

В данном диалоге основной темой разговора является обсуждение вопроса передачи диктором М1 неких материальных предметов, для наименования которых используется слово «рыба» («рыбы»). В частности, диктор М2 обращается к диктору М1 с распоряжением отдать/передать некие предметы в количестве 2 штук. Диктор М1 в ответной реплике демонстрирует непонимание/отсутствие у него возможности адекватного декодирования смыслового содержания речи диктора M2 с точки зрения количества предметов, подлежащих передаче: «... поточней бы как-нибудь, чтоб я все понял. Мне поделить то, что должен отдать или чего? Или три рыбы?». После чего диктор M2 разъясняет диктору M1, что при общем количестве материальных предметов в размере трех единиц, диктор М1 
должен отдать/передать две единицы и одну единицу до некоторого времени необходимо оставить у себя: «... две отдай, а одну оставь у себя пока». Диктор М1 сообщает о понимании смысла речи диктора М2 и согласии/готовности выполнить требуемое.

Об употреблении слова «рыба» в неузуальном значении и, как следствие, об использовании диктором М2 приема маскировки свидетельствует смысловое содержание интеракции, демонстрирующей со стороны диктора М1 сначала непонимание, а затем (после полученного от диктора М2 разъяснения) адекватное декодирование им прагматического смысла и информационного содержания высказывания: «...Все, все. Понял, а то я хотел соленой рыбы бежать покупать». Как видно, использование приема маскировки одним из участников коммуникации требует от собеседника определенных интерпретационных усилий для выведения реального смысла высказывания. Однако отсутствие в дальнейшем в речи диктора M1 высказываний, направленных на уточнение и самой ситуации, и отдельных ее элементов, свидетельствует о наличии у обоих коммуникантов предварительного знания о ситуации их межличностного взаимодействия, которое является основой и ориентиром для адекватной интерпретации содержания языковых единиц [Борисова, 2009]. В скобках заметим, что в данном примере приведена лишь часть проведенного исследования, в результате которого, однако, однозначно установить маскируемый объект речи не представилось возможным.

Приведенные примеры демонстрируют использование в качестве средства маскировки речевого приема криптономазии, когда для обозначения табуированного смысла вместо узуального, соответствующего речевым конвенциям понятия используется альтернативная номинация, не имеющая связи с денотативным содержанием исходного понятия. Подобная замена всегда ситуативно и/или контекстуально обусловлена и, как правило, имеет коммуникативную пресуппозицию: либо участники коммуникации заранее договариваются об использовании определенного речевого кода (как в приведенном примере с бочками), либо имеют представление о ситуации взаимодействия, что позволяет адекватно декодировать смысл передаваемого сообщения при отсутствии предварительной договоренности. В противном случае интерпретация закодированного сообщения требует дополнительных интерпретационных усилий с учетом лингвистических и экстралингвистических факторов. Лингвистическая экспертиза производится лицом, которое не обладает знаниями о неотраженной в речи коммуникативной пресуппозиции, и задача эксперта состоит в том, чтобы с опорой исключительно на контекст путем лексико-семантического анализа установить наличие признаков маскировки, средств ее реализации и, при наличии возможности, маскируемый предмет речи и/или его характеристики.

Таким образом, в терминологическом смысле, на наш взгляд, понятие маскировки соотносится с явлением криптолалии и обозначает реализацию в речи коммуникативной установки сокрытия информации от контрагента (третьего лица) посредством использования различных речевых приёмов и средств непрямой коммуникации. В заключение отметим, что вопрос об объеме и содержании понятия маскировки в судебной лингвистической экспертизе требует дальнейшего обсуждения с целью выработки единого научно обоснованного подхода к определению данного понятия и оптимизации процесса исследования, в том числе путем систематизации на основе обобщения экспертной практики основных речевых приемов и способов реализации коммуникативной установки сокрытия информации.

\section{Литература}

1. Борисова И.Н. Русский разговорный диалог: Структура и динамика. М., 2009.

2. Выразительные средства современной русской речи. Тропы и фигуры. Терминологический словарь/ В.П. Москвин. Ростов-на-Дону, 2007.

3. Гомон Т.В. Судебно-автороведческая экспертиза текстов документов, составленных с намеренным искажением письменной речи: дис. ... канд. юр. наук. Москва, 1992.

4. Доронина С.В. «Командир! Может, договоримся?»: приемы дискурсивного анализа в лингвистической экспертизе текстов по антикоррупционным делам. Политическая лингвистика. 2015. № 3 (53).

5. Козлов А.Е., Саженина Я.Х. Семантические и прагматические показатели маскировки в экономических преступлениях. Лингвокультурология, 2016. URL: https://cyberleninka.ru/article/n/semanticheskie-i-pragmaticheskiepokazateli-maskirovki-v-ekonomicheskih-prestupleniyah.

6. Кусов Г.В. Использование специальной терминологии в судебной лингвистической экспертизе. Юридические науки. Теория и практика общественного развития. 2011. № 6. URL: http://teoriapractica.ru/rus/files/arhiv zhurnala/2011/5/yurisprudentsiya/kusov.pdf/.

7. Москвин В.П. Эвфемизмы в лексической системе современного русского языка, Москва, 2007.

8. Москвин В.П. Эвфемизмы: системные связи, функции и способы образования. Вопросы языкознания. 2001 . № 3.

9. Никитина А.М. К вопросу об эвфемии: этико-риторический аспект. Наука и школа. - 2011. Вып. 5. URL: https://cyberleninka.ru/article/n/k-voprosu-ob-evfemii-etiko-ritoricheskiy-aspekt.

10. Судебная лингвистика: монография/ О.Н. Матвеева, Н.В. Вязигина, Ю.В. Холоденко, С.И. Кузеванова, М.Е. Маргольф, А.А. Селина/ Под ред. О.Н. Матвеевой. Барнаул, 2015. 


\section{References}

1. Borisova, I. N. (2009). Russian spoken dialogue: Structure and dynamics [Russkiirazgovornii dialog: strukturaidinamica]. Moscow (in Russian).

2. Doronina, S. V. (2015). Let`s agree, commander! The methods of discourse analysis in linguistic expertise of texts on anti-corruption cases [Komandir! Moget, dogovorimsya? Priemi diskursivnogo analiza $\vee$ lingvisticheskoi ekspertize po antikorruptsionnim delam]. Political linguistics, 3(53) (in Russian).

3. Gomon, T. V. (1992). Forensic author studies examination of the texts of documents drawn up with the deliberate distortion of writing. Thesis of Doctoral Dissertation. [Sudebno-avtorovedcheskaya ekspertiza tekstov dokumentov, sostavlennih s namerennim iskazheniem pismennoi rechi]. Moscow (in Russian).

4. Kozlov, A. E., Sazhenina, Y. H. (2016). Semantic and pragmatic indicators of disguise in economic crimes. Cultural linguistics. Available from: https://cyberleninka.ru/article/n/semanticheskie-i-pragmaticheskie-pokazateli-maskirovki-vekonomicheskih-prestupleniyah/ (in Russian).

5. Kusov, G. V. (2011). The use of special terminology in forensic linguistic expertise. Legal science [Ispolzovanie spesialnoy terminologii $v$ sudebnoy lingvisticheskoy ekspertize]. Theory and practice of social development, 6. Available from: http://teoria-practica.ru/rus/files/arhiv zhurnala/2011/5/yurisprudentsiya/kusov.pdf/ (in Russian).

6. Matveeva, O. N., Vaizigina, N. V., Kholodenko, Y. V., Kuzevanova, S. I., Margolf, M. E., \& Selina, A.A. (2015). Forensic linguistics: monograph. [Sudebnaya lingvistika]. Barnaul (in Russian).

7. Moskvin, V. P. (2001). Euphemisms: system connections, functions and methods of creation. [Euphemismi: sistemnie svyazi, funkzii I sposobi obrazovaniya]. Questions of linguistics, 3 (in Russian).

8. Moskvin, V. P. (2007a). Euphemisms in the lexical system of the modern Russian language [Euphemismi v leksicheskoy sisteme sovremennogo russkogo yazika]. Moscow (in Russian).

9. Moskvin, V. P. (2007b). Expressive means of modern Russian speech. Trails and figures. Terminological dictionary. [Virazitelnie sredstva sovremenoy russkoy rechi. Tropy I figury. Terminjlogicheskiy slovar]. Rostov-on-Don (in Russian).

10. Nikitina, A. M. (2011). To the question about Eufemia: ethical and rhetorical aspects. Science and School, 5. Available from: https://cyberleninka.ru/article/n/k-voprosu-ob-evfemii-etiko-ritoricheskiy-aspekt/ (in Russian).

\section{Citation:}

Дайлоф Е.Л. О терминологическом смысле понятия «маскировка» в контексте судебной лингвистической экспертизы.

// Юрислингвистика. - 2019. - 11. - 24-28

Dailof, E.L. (2019). "Disguise" meaning in forensic linguistic expertise. Legal Linguistics, 11, 24-28. 